\title{
Learning motivation and perfectionism in English language learning: An analysis of Taiwanese university students
}

Chen, Kate Tzu-Ching $₫$

Chaoyang University of Technology, Taiwan (katechen@cyut.edu.tw)

Kuo, Julia Ya-Chu

Chaoyang University of Technology, Taiwan (blue_julia530@hotmail.com)

Kao, Po-Chi

Chang Gung University, Taiwan (mk@mail.cgu.edu.tw)

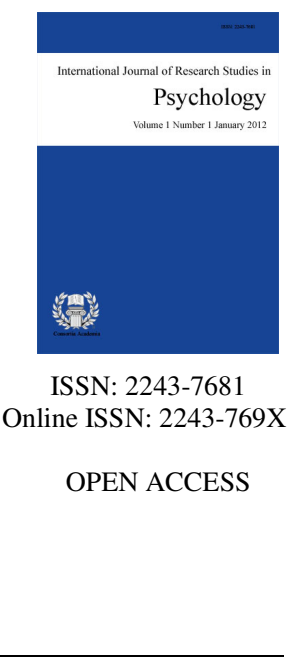

\section{Abstract}

This study aimed to identify the interrelations among background characteristic, measures of learning motivation and the dimension of perfectionism among Taiwanese English as foreign Language (EFL) university students. The instruments were a Likert-scale survey questionnaire which consisted of (1) the Work Preference Inventory (Students Version) created by Amabile, Hill, Hennessey, and Tighe (1994); and (2) the Multidimensional Perfectionism Scale designed by Hewitt and Flett (1991). The results indicated that most students were intrinsically-motivated and were self-oriented perfectionists. It was found that both intrinsic and extrinsic motivations were significantly and positively associated with self-oriented perfectionism for EFL learning. The results also indicated that perfectionism differs significantly among the participated students in terms of age and majors. Students who aged 18 showed higher positive levels for perfectionism than students aged 20 and students from management majors had significantly higher perfectionism tendencies.

Keywords: English as a foreign language (EFL); extrinsic motivation; intrinsic motivation; university students; self-oriented perfectionism; socially-prescribed perfectionism; other-oriented perfectionism 


\section{Learning motivation and perfectionism in English language learning: An analysis of Taiwanese university students}

\section{Introduction}

Many researchers had studied the effects of different personality factors on learning in fields other than English as Foreign Language (EFL) (e.g. Carrell, Prince, \& Astika, 1996). Personality, which makes a person distinct from everyone else, is an interesting and intriguing aspect of humans. It can be broken down into seven primary traits: self-esteem, inhibition, risk-taking, empathy, extroversion/introversion, perfectionism, and motivation, all of which have been investigated widely by psychology scholars (Brown, 2007). This study focused on the last two traits in relation to their contributions to achievement in EFL learning. In a study investigating university students' perfectionism, motivation, and motivational strategies for learning, Mills and Blankstein (2000) revealed that perfectionists have higher levels of motivation in whatever they do. Perfectionism and motivation are the most influential factors in academic performance, and this has initiated much research over the past few decades (Brackney \& Karabenick, 1995; Mills \& Blankstein, 2000; Miquelon, Vallerand, Grouzet, \& Cardinal, 2005). Although many researchers have used these two factors to predict a learner's performance in language learning, the ways in which perfectionism and motivation interact with each other remain unknown. Additionally, studies on these two factors have been conducted mostly in the United States (Accordino, Accordino, \& Slaney, 2000; Mills \& Blankstein, 2000; Miquelon et al., 2005). This study probed the personality perspectives of EFL learners studying at university level in Taiwan, focusing on two major personality factors that affect EFL learning, namely learning motivation and perfectionism. In particular, the investigation looked closely at whether perfectionists have strong levels of learning motivation that gives them valuable momentum to learn English and to seek perfect achievements.

Learning motivation has been the focus of intense and fruitful research over the past two decades (Donitsa-Schmidt, Inbar, \& Shohamy, 2004; Dörnyei, 1994, 2003; Ely, 1986; Gardner \& MacIntyre, 1993; Hiromori, 2009; Wu, 2003). Motivation is one of the various factors that influence how people think and behave, especially in language learning (Gardner \& MacIntyre, 1993; Paul, Ludwi, \& Andrew, 1962). Some of the research results from Taiwan have further indicated that low motivation leads to low achievement in EFL learning among Taiwanese students (Liao, 2010). Perfectionism, however, is often considered a negative trait, one leading to abnormal and neurotic behavior (Flett, Hewitt, \& Dyck, 1989; Pacht, 1984). It has widely been believed that people of the high perfectionism type usually exhibit negative symptoms common in clinical cases, such as depression, eating disorders, suicidal tendencies, procrastination, and so on (Chan, 2009). However, perfectionism can also be a positive trait (Hamachek, 1978) as it appears that being a perfectionist is not all negative and can help one to achieve one's goals. In the last decade, a considerable amount of research has been focused on perfectionism (Cook \& Kearney, 2009; Enns, Cox, \& Clara, 2002; Flett, Blankstein, Hewitt, \& Koledin, 1992; Flett, 35 Hewitt, \& Blanksten, 1991; Terry-Short, Owens, Slade, \& Dewey, 1995). Today, EFL learning had become a worldwide trend, but insufficient research were found to explore motivation and perfectionism, and that particularly linked these two factors to EFL learning. Consequently, this study focused on motivation and perfectionism in relation to EFL learning and addressed the differences between participants' background characters and these two variables.

\section{Literature Review}

\subsection{Language learning motivation}

Recently, many researchers specializing in foreign language education and psychology have been investigating the relationship between motivation and English learning because of its fascinating elements. These 
"involve the reasons why we want to learn, the strength of our desire to learn, the kind of person we are, and the task and estimation of what it requires of us" (McDonough, 2007, p. 369). Keller (1983) further claimed that motivation is "the choices people make as to what experiences or goals they will approach or avoid and the degree of effort they will exert in that respect" (p. 389). Along similar lines, "Motivation is a process whereby a certain amount of instigation force arises, initiates action, and persists as long as no other force comes into play to weaken it and thereby terminate action, or until the planned outcome has been reached" (Dörnyei, 1998, p. 118). It is, therefore, obvious that motivation is the driving force that enables us to achieve our goals, which is why for a couple of decades now, motivation has been an important topic in education (Lim, 2004). According to Brown (1980), motivation can even be a suitable explanation as to why someone succeeds or fails in a simple or complex task. This concept also applies to language learning, and whether one is motivated or not can greatly influence someone's language learning outcome. Research has shown that learning motivation has a significant effect on the learning results of a second language (SL) or a foreign language (FL) (Dörnyei, 1994 \& 2003; Oxford \& Shearin, 1994).

Some researchers have studied learning motivation for several decades in an attempt to classify it into generally-accepted categories. For example, Gardner and Lambert (1959) divided motivation into integrative and instrumental motivation. Integrative motivation refers to the desire to become a member of the second language (L2) community, triggering people to acquire and learn a second or foreign language. In contrast, instrumental motivation refers to the actual gains received after acquiring or learning the second or foreign language. These gains can be praise from teachers, instructors, classmates, or family members; money; or a better job. Lambert (1974) further stated that people with integrative motivation have a passion and interest "in people and culture represented by the other language group" (p. 98). That is to say, these people are fascinated by those who speak different languages and they are attracted to their cultures. Instrumental motivation, on the other hand, is a desire to earn rewards by achieving a certain standard of English learning.

In 1994, however, Amabile et al. divided motivation into two major categories: intrinsic motivation and extrinsic motivation. Intrinsic motivation is "the motivation to engage in work primarily for its own sake, because the work itself is interesting, engaging, or in some way satisfying" (p. 950). Such motivation also refers to learners' feelings when they need to complete or comprehend the purpose of their learning, for example, when people study to gain required knowledge. In other words, intrinsic motivation is an internal incentive, a response to a need. This kind of motivation is inside the learners' minds and can be triggered by simple curiosity or by the need for knowledge. In summary, intrinsic motivation is more closely related to one's own thoughts. If one wants to fulfill one's own needs or reach a standard to which one aspires, that desire is "intrinsic motivation".

Amabile describes its counterpart, extrinsic motivation, as "the motivation to work primarily in response to something apart from the work itself" (p. 950). Extrinsic motivation refers to external rewards received from others, such as praise from teachers, money, high grades, and so on. It is "a construct that pertains whenever an activity is done in order to attain some separable outcomes" (Ryan \& Deci, 2000, p. 60). That is, "Extrinsically motivated behaviors are carried out in anticipation of a reward from outside and beyond the self" (Brown, 2007, p. 88). Thus, behavior such as trying to avoid punishment, attending a competition, or studying for an exam, or behavior related to other outside forces, is seen as externally motivated. In short, extrinsic motivation is more closely related to a person's external environment and is due to others, not due to oneself.

In summary, learning is often treated as work, and whether people are motivated or not depends on the work (or learning) itself. If people consider work (learning) to be interesting and challenging enough to hold their attention, they will tend to have intrinsic motivation. In contrast, people who consider that they should be paid for their work (learning), or earn rewards from the work (learning), tend to have extrinsic motivation. In this study, Amabile et al.'s classification of motivation (1994) was used to determine the types of learning motivation experienced by university EFL freshmen learners as this is a category of study that has not been widely explored in Taiwan before. 
As to the relationship between intrinsic and extrinsic motivation, Lepper and Greene (1978), have proposed that an "individual's intrinsic motivation will decrease to the extent that their extrinsic motivation increases, a position implicitly held by other theorists" (p. 113). It is certainly true that many other researchers have determined that intrinsically motivated behavior appears when extrinsic motivators are absent (e.g., Deci, 1975; Lepper, Greene, \& Nisbett, 1973). However, a few theorists (e.g., Deci \& Ryan, 1985) have suggested that, under certain circumstances, intrinsic and extrinsic motivation need not work in opposition. In other words, intrinsic motivation and extrinsic motivation, not necessarily being opposites, can sometimes coexist. The theories and statements about motivation discussed above can be applied to motivation in learning, which includes EFL learning.

\subsection{Perfectionism}

Perfectionism, a major personality trait, has been a widespread focus of interest in psychology since the mid-nineteenth century (Adler, 1956; Hewitt et al., 1991; Mills \& Blankstein, 2000; Onwuegbuzie \& Daley, 1999; Pacht, 1984). According to Adler (1956), people living a goal-oriented life have an innate motivation that triggers them to seek excellence. This excellence can be described by the term 'perfect'. In addition, perfectionists tend to be dissatisfied with their achievements, and try to hide their weaknesses. They may also want to gain attention from other people and to be liked by others. Thus, perfectionists may pursue making themselves better for their own glory.

Perfectionism is "the practice of demanding of oneself or others a higher quality of performance than is required by the situation" (Hollender, 1978, p. 384). Generally, perfectionism is defined as a tendency to set high, or even unreachable, standards of performance (Hewitt et al., 1991) and to judge one's worth by one's own performance (Pacht, 1984). In 1991, Hewitt et al. proposed three dimensions of perfectionism and developed a self-reporting questionnaire that measured the different components. The first dimension, self-oriented perfectionism, refers to when people set high standards for themselves and engages in intense self-criticism. People of this type are rarely satisfied with the final result. Socially-prescribed perfectionism, the second type, refers to a desire to fulfill others' expectations. Those with this type of perfectionism try hard to achieve the goals set by others in order to please the goal-setters. The third type is other-oriented perfectionism. People with this type of perfectionism tend to ask others to achieve the goals that they themselves have set. Such people set high goals for others and demand that these other people achieve them.

\subsection{The relationship between learning motivation and perfectionism}

Although a great deal of research has been conducted on learning motivation and perfectionism, very few studies have addressed the association between these two variables. Blasberg (2006), for example, reported in his study on the relationships among perfectionism, achievement motivation, and conscientiousness, that a learner's motivation is highly related to perfectionism. Another study, undertaken by Mills and Blanksten in 2000, indicated that self-oriented perfectionism is related to extrinsic motivation, as those with self-oriented perfectionism are motivated by recognition of their academic work. In addition, being sensitive to others' opinions of their work and ideas, self-oriented perfectionists usually compare their success to that of others. It is also known that socially-prescribed perfectionism is related to extrinsic motivation. The recognition of others is the main impetus that motivates such people to be perfect. It follows that other-oriented perfectionism is significantly associated with extrinsic motivation. However, to the researchers' knowledge, no researchers have investigated the relationships between these characteristics in the field of EFL learning.

\section{Methodology}

\subsection{Participants}

Students enrolled in English classes in their first year of university were chosen as the target population for 
this study. This is because, in Taiwanese universities, first-year students are the only group required to take integrated English skills courses. Due to the large population of university freshmen in Taiwan and the difficulty and cost of constructing a complete list of the population, cluster sampling was used to overcome any losses in precision. A total of 371 students across eight universities returned the questionnaires. Of these, 226 were female (60.4\%) and 145 were male (39.1\%). Two respondents $(0.5 \%)$ did not report their gender. The mean age of the respondents was 18.9 ( $\mathrm{SD}=1.8478$ ). According to the valid responses, most of the respondents were from the schools of Management (31\%), followed by those from the Humanities and Social Sciences (25.9\%), Agriculture (20.5\%), Engineering (11.9\%), and Information (10.5\%). One datum was missing $(0.3 \%)$.

\subsection{Instrument}

This study adopted the survey method, using two scales in one questionnaire: (1) the Work Preference Inventory (Students Version) created by Amabile et al. (1994); and (2) the Multidimensional Perfectionism Scale designed by Hewitt et al. (1991). The questionnaire also included a section on the participants' background characteristics, specifically gender, age and major. The researcher distributed 400 questionnaires, and 371 were returned, a response rate of $92.75 \%$.

The Work Preference Inventory-Student Version (WPI-S) - The Work Preference Inventory, developed by Amabile et al. (1994), is used to determine people's intrinsic/extrinsic motivation type. The WPI-S, which contains 30 items, is a self-reporting questionnaire with a four-point Likert-type scale of responses ranging from 1 (never or almost never true of me) to 4 (always or almost always true of me). It contains two main categories: intrinsic motivation (concerned with self-determination, competence, task involvement, curiosity, enjoyment and interest) and extrinsic motivation (concerned with competition, evaluation, recognition, money, or other tangible incentives and constraint by others). The two main categories each consist of two subscales: (1) Intrinsic motivation consists of enjoyment (items 7, 8, 9, 14, 17, 20, 23, 27, 28, and 30) and challenge (items 3, 5, 11, 13, and 26); (2) extrinsic motivation is subcategorized as outward (items 1, 2, 6, 12, 15, 18, 21, 24, 25, and 29) and compensation (items 4, 10, 16, 19, and 22). The Cronbach's alphas for the WPI-S are .79 for intrinsic motivation and .78 for extrinsic motivation. It has a meaningful factor structure, adequate internal consistency, good short-term test-retest reliability, and good longer-term stability (Amabile et al., 1994).

The Multidimensional Perfectionism Scale (MPS) - MPS is a 45-item self-reported measurement designed by Hewitt et al. (1991), which is used to assess the dimension of perfectionism. Items are scored on a Likert-type scale of 1 (Disagree) to 7 (Agree). Perfectionism is categorized into three types: (1) self-oriented perfectionism: setting high standards and unrealistic goals for oneself (items 1, 6, 8, 12, 14, 15, 17, 20, 23, 28, 32, 34, 36, 40, and 42); (2) socially-prescribed perfectionism: trying to meet standards set by others in order to please those others (items 5, 9, 11, 13, 18 21, 25, 30, 31, 33, 35, 37, 39, 41, and 44); and (3) other-oriented perfectionism: setting goals for others and asking others to meet those goals (items 2, 3, 4, 7, 10, 16, 19, 22, 24, 26, 27, 29, 38, 43, and 45). Each dimension of the MPS scored high Cronbach's alphas: .86 for self-oriented perfectionism, .82 for other-oriented perfectionism, and .87 for socially-prescribed perfectionism. Unlike other perfectionism scales, the MPS is constructed with a broad view of perfectionism itself (Frost, Marten, Lahart, \& Rosenblate, 1990).

The WPI-S and MPS and were originally written in English. However, the participants in the current study were Taiwanese. Thus, the two original questionnaires were first translated into Mandarin Chinese to ensure precise responses. Also, the researcher conducted a pilot study to measure the validity and reliability of the translated versions of the instruments in which forty EFL university students were told to write in suggestions, comments, and feedback regarding the questionnaire items. The Cronbach's alphas of the Chinese versions questionnaire of both scales are shown in Table 1, which indicated that the consistency and stability of the MPS and WPI-S reflected true measurement. 


\subsection{Data analysis}

The collected data were coded and analyzed using SPSS version 20. The descriptive statistics represent the means, standard deviations, and reliability of the Multidimensional Perfectionism Scale (MPS) and the Work Preference Inventory-Student Version (WPI-S). The Pearson's product-moment correlation coefficient was used to probe the relationship between motivation and perfectionism and the sub-categories of these two variables. Then t-test and one way ANOVA were used to determine whether there was a statistically among participants" background characteristics, motivation and perfectionism. The significance level was set at .05.

\subsection{Procedures}

Before conducting the formal study, the researcher sent e-mails to selected instructors of university freshman English courses in Taiwan to seek their assistance in distributing the questionnaires. The participating instructors were asked to explain the purpose of the study and the procedure for completing the questionnaire to their participating students. Students were also informed by their instructors that their participation was voluntary, confidentiality would be maintained, and that the questionnaires would not be marked or affect their grades. After the questionnaires were completed, the instructors returned the completed questionnaires to the researcher. In reference to the research questions, the participants' learning motivations and perfectionism types, and the relationships between these two personality factors, were then analyzed. The differences between the participants' background characteristics and possible relationships to their learning motivation and perfectionism types were then examined.

\section{Results}

\subsection{Descriptive statistics}

The means, standard deviations, and reliabilities of the WPI-S and the MPS for the total sample are presented in Table 1. With respect to the WPI-S, students presented higher levels of enjoyment motivation than of outward motivation. With respect to the MPS, the results indicated that most of the students were self-oriented perfectionists $(M=44.28)$ who were extrinsically motivated $(M=60.95)$. Comparing the results of this study with the original results of Hewitt et al. (1991), it appears that students in both the United States and Taiwan are self-oriented perfectionists. However, in the US, fewer students are socially-prescribed perfectionists, and in Taiwan, fewer students are other-oriented perfectionists.

\section{Table 1}

Means, standard deviations, and reliabilities for the WPI-S and the MPS for the total sample $(n=371)$

\begin{tabular}{lccc}
\hline & $\mathrm{M}$ & $\mathrm{SD}$ & Cronbach's $\alpha$ \\
\hline WPI-S & 2.847 & .25152 & .891 \\
Intrinsic motivation & 2.934 & .33879 & .808 \\
Challenge & 2.850 & .44088 & \\
Enjoyment & 3.018 & .34161 & \\
Extrinsic motivation & 2.756 & .24598 & .967 \\
Outward & 2.817 & .28813 & \\
Compensation & 2.691 & .31967 & .743 \\
MPS & 4.216 & .37499 & .780 \\
Self-oriented & 4.217 & .51961 & .762 \\
Socially prescribed & 4.217 & .43507 & .734 \\
Other-oriented & 4.216 & .43542 & \\
\hline
\end{tabular}

\subsection{Pearson correlation results}

The Pearson correlations between the scales of the WPI-S and the MPS are presented in Table 2. The result 
yielded a significantly positive low correlation $(r=.145 ; p<.05)$ between the WPI-S and the MPS. Furthermore, the Pearson correlation between the sub-categories of WPI-S and the MPS are shown in Table 3. With respect to the WPI-S, socially- oriented perfectionism had significant low to medium correlation with both intrinsic motivation $(r=.359 ; p<.05)$ and extrinsic motivation $(r=.188 ; p<.05)$. However, enjoyment $(r=.-118, p<.05)$ significantly but negatively correlated with other-oriented perfectionists in English learning.

With respect to the MPS, self-oriented perfectionism was significantly and positively related to both the intrinsic $(r=.359, p<.05)$ and extrinsic $(r=.188, p<.05)$ motivation and the sub-categories of enjoyment $(r$ $=.269, p<.05)$, challenge $(\mathrm{r}=.383, p<.05)$, outward $(r=.135, p<.05)$ and compensation $(r=.193, p<.05)$ in a low to medium level. Other-oriented perfectionism was significantly negatively related to the sub-categories of enjoyment $(r=-.118, p<.05)$.

Table 2

Pearson correlations between the WPI-S and the MPS for the total sample $(n=371)$

\begin{tabular}{llll}
\hline & & WPI-S & MPS \\
\hline MPS & Pearson correlation & 1 & $.145^{*}$ \\
& Sig. (2-tailed) & & .005 \\
\hline Note $* * p<0.05$ & &
\end{tabular}

Table 3

Correlations between the subcategories of the WPI-S and the MPS (n=371)

\begin{tabular}{lccc}
\hline & $\begin{array}{c}\text { Self-oriented } \\
\text { perfectionism }\end{array}$ & $\begin{array}{c}\text { Other-oriented } \\
\text { perfectionism }\end{array}$ & $\begin{array}{c}\text { Socially-prescribed } \\
\text { perfectionism }\end{array}$ \\
\hline Intrinsic motivation & $.359^{*}$ & -.097 & -.057 \\
Enjoyment & $.269^{*}$ & $-.118^{*}$ & -.064 \\
Challenge & $.383^{*}$ & -.039 & -.031 \\
Extrinsic motivation & $.188^{*}$ & .070 & .056 \\
Outward & $.135^{*}$ & .083 & .044 \\
Compensation & $.193^{*}$ & .013 & .050 \\
\hline Note $* p<0.05$ & & &
\end{tabular}

\subsection{Demographic characteristics analysis results}

As shown in Table 4, the T-test results indicated that there was no significant difference in terms of gender on the WPI-S and MPS. Similarly, as shown in Table 5, the one way ANOVA results revealed that the significance of the WPI-S did not reach the .05 level. This lack of significance indicated that the respondents' ages did not influence their learning motivation types. However, the final results of the one way ANOVA revealed that the respondents had significantly different views of perfectionism $(F=5.310, p<.05)$. Therefore, the researcher further used the Post hoc test to identify the differences between the age groups. The results indicated significant differences between age groups (Sig. $=.000, p<.05)$. Respondents aged 18 and those aged 20 had contradictory ideas on the MPS.

\section{Table 4}

T-test Results of the WPI-S and the MPS between gender $(n=371)$

\begin{tabular}{llccccc}
\hline & Gender & $N$ & $M$ & $S D$ & $T$ & Sig. \\
\hline \multirow{2}{*}{ WPI-S } & Male & 145 & 85.72 & 8.03 & \multirow{2}{*}{.225} & .822 \\
& Female & 224 & 85.91 & 6.90 & & .360 \\
& Male & 145 & 167.43 & 23.16 & .719 \\
\hline
\end{tabular}

Note. $* p<0.05$ 
As shown in Table 5, the differences in respondents' type of perfectionism were identified according to college majors. The significance of the MPS $(F=1.286, p<.05)$ reached the .05 level, which means that the respondents' majors significantly influenced their perfectionism type. The Post hoc test was then applied to investigate the differences by college major in perfectionism. A significant difference was found. Students from management colleges $($ Sig. $=.003, \mathrm{p}<.05$ ) had higher perfectionism tendencies than students from any other colleges.

Table 5

ANOVA tests of demographic characteristics toward WPI-S and MPS

\begin{tabular}{llccccl}
\hline \multirow{2}{*}{ Demographic } & & Levene & ANOVA & & \\
\cline { 3 - 7 } & & & Sig, & F & Sig. & Post Hoc \\
\hline Age & WPI-S & 1.252 & .289 & .787 & .534 & No significance \\
\multirow{2}{*}{ Major } & MPS & 2.561 & .038 & 5.310 & $.000 *$ & $20>22>19>21>18$ \\
& WPI & .139 & .968 & 1.731 & .103 & No significance \\
& MPS & 3.122 & .015 & 1.286 & $.003 *$ & Management $>$ agriculture $>$ Informational \\
& & & & & & technology $>$ Humanity $>$ Engineering \\
\hline
\end{tabular}

Note. ${ }^{*} p<.05 ; \mathrm{BG}=$ between group; $\mathrm{WG}=$ within group

\section{Discussion and Implication}

\subsection{Discussions}

Motivation among university students in EFL learning - Recently, some psychologists have considered whether motivation preferences could be influenced by the external world. However, students who are motivated intrinsically will perform better. In this study, the results showed that university students tend to demonstrate intrinsic motivation toward their EFL learning and believe that EFL learning is a source of enjoyment. This may be due to the fact that most university students care greatly about their schoolwork and usually work hard when learning English. This study is consistent with the results of Chiou's study of 2000, which found that Taiwanese students tend to have high levels of intrinsic motivation. However, students in this study tended to have high levels of enjoyment motivation toward learning EFL, while those in Chiou's study had higher levels of outward motivation.

Perfectionism among university students in EFL learning - The present study found that the majority of students tended to be self-oriented perfectionists. They possessed irrational expectations and high standards for themselves that led to the internally motivated desire to be perfect. This tendency is followed by socially-prescribed perfectionism, whilst only a few students were other-oriented perfectionists. According to Hewitt et al. (1991) and to this study, it is apparent that both the majority of American and Taiwanese university students are self-oriented perfectionists. However, unlike American students, for whom the second type of perfectionism is other-oriented perfectionism, Taiwanese students have a greater tendency toward socially-prescribed perfectionism.

The relationship between WPI-S and MPS - This study found that most Taiwanese university students are intrinsically motivated, self-oriented perfectionists when it comes to EFL learning. There is also a significantly low positive relationship between learning motivation and perfectionism in EFL learning. That is to say, the students scoring higher for motivation tended to have higher perfectionism. In addition, there is a significantly low to medium positive relationship between learning motivation and self-oriented perfectionism. In addition, a significantly low negative relationship was found to exist between enjoyment motivation and other-oriented perfectionism. It is apparent that both intrinsic and extrinsic motivation can trigger self-oriented perfectionists' English learning. However, other-oriented perfectionists do not consider learning English to be enjoyable.

The difference between MPS and WPI-S based on the demographic data - This result is consistent with Amabile's (1994) study, in which no significant differences were found between males and females. Although 
motivation somehow influences both males and females, no significant differences were found between males and females in any category of the WPI-S. However, Chiou's (2000) study showed that females experience more enjoyment motivation than males, while males experience more challenge motivation than females. The results also indicate that there was no significant difference between males and females for the MPS. This result is consistent with the results in Hewitt and Flett's (1991) study on learner's perfectionism, in which they did not find any differences between the genders.

The results also indicated that age is not the factor to influence participants' learning motivation, and nor does major. However, participants' age and college majors significantly influence their perfectionism type. Practically, respondents aged 18 and from the Management majors have higher perfectionism tendencies than students aged 20 and from Agriculture majors. The final results show that students vary in their types of perfectionism according to their age and college majors, but not gender. This result is consistent with the previous studies done by Hewitt and Flett in 1991 on differences in gender which do not influence participants' perfectionism.

\subsection{Implications}

Since most students are self-oriented perfectionists and tend to have intrinsic motivation toward their EFL learning, educators should try to advance the learner's EFL learning, possibly by using a variety of teaching methods to cope with their perfectionism orientation and to further increase their learning motivation. For instructors and teachers, understanding each learner's motivation and type of perfectionism would help them to apply proper strategies when teaching their students. In summary, this study contributes to the literature by providing valuable insights and a more comprehensive view on learning motivation and perfectionism. However, the literature in the related field is not yet complete enough to provide a deeper understanding of multidimensional leaning motivation and perfectionism among university students or those in other age groups. Future research should also consider comparing university students from different countries. It is also imperative to investigate the role of other potential variables and their relationship with learning motivation and perfectionism.

\section{References}

Accordino, D. B., Accordino, M. P., \& Slaney, R. B. (2000). An investigation of perfectionism, mental health, achievement and achievement motivation in adolescents. Psychology in the Schools, 37(6), 535-545. http://dx.doi.org/10.1002/1520-6807(200011)37:6<535::AID-PITS6>3.0.CO;2-O

Adler, A. (1956). The neurotic disposition. In H. L. Ansbacher \& R. R. Ansbacher (Eds.), The individual psychology of Alfred Adler (pp.239-262). New York: Harper.

Amabile, T. M., Hill, K. G., Hennessey, B.A., \& Tighe, E. M. (1994). The work preference inventory: assessing intrinsic and extrinsic motivational orientations. Journal of Personality and Social Psychology, 66, 950-967. http://dx.doi.org/10.1037/0022-3514.66.5.950

Blasberg, J. S. (2006). Perfectionism and positive and negative outcomes: Can achievement motivation and conscientiousness account for “adaptive perfectionism?” Unpublished master's thesis, The University of British Columbia, Vancouver.

Brackney, B. E., \& Karabenick, S. A. (1995). Psychopathology and academic performance: The role of motivation and learning strategies. Counseling Psychology, 42(4), 456-265. http://dx.doi.org/10.1037/0022-0167.42.4.456

Brown, H. D. (1980). The optimal distance model of second language acquisition. TESOL Quarterly, 14, 157-164. http://dx.doi.org/10.2307/3586310

Brown, H. D. (2007). Principles of language learning and teaching (5 $5^{\text {th }}$ ed.). White Plains, NY: Pearson Education.

Carrell, P. L., Prince, M. S., \& Astika, G. G. (1996), Personality types and language learning in an EFL context. Language Learning, 46, 75-99. http://dx.doi.org/10.1111/j.1467-1770.1996.tb00641.x 
Chan, D. W. (2009). Perfectionism and goal orientations among Chinese gifted students in Hong Kong. Roeper Review, 31(1), 9-17. http://dx.doi.org/10.1080/02783190802527331

Chiou, H. J. (2000). Intrinsic and extrinsic work motivation: A quantitative study of motivational orientations for Taiwanese and American undergraduates. Research in Applied Psychology, 7, 221-251.

Cook, L. C., \& Kearney, C. A. (2009). Parent and youth perfectionism and internalizing psychopathology. Personality and Individual Differences, 46, 325-33. http://dx.doi.org/10.1016/j.paid.2008.10.029

Deci, E. L. (1975). Intrinsic motivation. New York: Plenum Press. http://dx.doi.org/10.1007/978-1-4613-4446-9

Deci, E., \& Ryan, R. M. (1985). Intrinsic motivation and self-determination in human behavior. New York, NY: Plenum Press. http://dx.doi.org/10.1007/978-1-4899-2271-7

Donitsa-Schmidt, S., Inbar, O., \& Shohamy, E. (2004). The effects of teaching spoken Arabic on students' attitudes and motivation in Israel. The Modern Language Journal, 88(2), 217-228. http://dx.doi.org/10.1111/j.0026-7902.2004.00226.x

Dörnyei, Z. (1994). Motivation and motivating in the foreign language classroom. The Modern Language Journal, 78(3), 273-284. http://dx.doi.org/10.1111/j.1540-4781.1994.tb02042.x

Dörnyei, Z. (1998) Motivation in second and foreign language learning. Language Teaching Research, 31, 117-135. http://dx.doi.org/10.1017/S026144480001315X

Dörnyei, Z. (2003). Attitudes, orientations, and motivations in language learning: advances in theory, research, and applications. Language Learning, 53(1), 3-32. http://dx.doi.org/10.1111/1467-9922.53222

Ely, C. M. (1986). An analysis of discomfort, risk taking, sociability, and motivation in the L2 classroom. Language Learning, 36(1), 1-25. http://dx.doi.org/10.1111/j.1467-1770.1986.tb00366.x

Enns, M. W., Cox, B. J., \& Clara, I. (2002). Adaptive and maladaptive perfectionism: developmental origins and association with depression proneness. Personality and individual differences, 33, 921-925. http://dx.doi.org/10.1016/S0191-8869(01)00202-1

Flett, G. L., Blankstein, K. R., Hewitt, P. L., \&. Koledin, S. (1992). Components of perfectionism and procrastination in college students. Social behavior and personality, 20(2), 85-94. http://dx.doi.org/10.2224/sbp.1992.20.2.85

Flett, G. L., Hewitt, P. L., \& Blankstein, K. R. (1991). Dimensions of perfectionism and irrational thinking. Rational-Emotive \& Cognitive-Behavior Therapy, 9(3), 185-201. http://dx.doi.org/10.1007/BF01061229

Flett, G. L., Hewitt, P. L., \& Dyck, D. G. (1989). Self-oriented perfectionism, neuroticism, and anxiety. Personality and Individual Differences, 10, 731-735. http://dx.doi.org/10.1016/0191-8869(89)90119-0

Frost, R. O., Marten, P., Lahart, C., \& Rosenblate, R. (1990). The dimensions of perfectionism. Cognitive Therapy and Research, 14(5), 449-468. http://dx.doi.org/10.1007/BF01172967

Gardner, R. C., \& Lambert, W. E. (1959). Motivational variables in second language acquisition. Canadian Journal of Psychology, 13, 266-272. http://dx.doi.org/10.1037/h0083787

Gardner, R. C., \& MacIntyre, P. D. (1993). On the measurement of affective variables in second language learning. Language Learning, 43(2), 157-194. http://dx.doi.org/10.1111/j.1467-1770.1992.tb00714.x

Hamachek, D. E. (1978). Psychodynamics of normal and neurotic perfectionism. Psychology, 15, $27-33$.

Hewitt, P. L., \& Flett, G. L (1991). Perfectionism in the self and social contexts: Conceptualization assessment, and association with psychopathology. Personality and social psychology, 60(3), 456-470. http://dx.doi.org/10.1037/0022-3514.60.3.456

Hiromori, T. (2009). A process model of L2 learners' motivation: From the perspectives of general tendency and individual differences. System, 37, 313-321. http://dx.doi.org/10.1016/j.system.2008.11.009

Hollander, M. H. (1978). Perfectionism, a neglected personality-trait. Journal of Clinical Psychiatry, 39, 384-390.

Keller, J. (1983). Motivational design of instruction. In C. Reigelruth (Ed.), Instructional design theories and models: An overview of their current status (pp. 383-434). Hillsdale, NJ: Lawrence Erlbaum Associates.

Lambert, W. E. (1974). Culture and language as factors in learning and education. In F. E. Aboud \& R.D. Meade (Eds.), Cultural factors in learning and education (pp. 91-122). Bellingham, Washington: Fifth Western Washington Symposium on Learning.

Lepper, M. R., \& Green, D. (1978). Overjustification research and beyond: Toward a meansends analysis of 
Learning motivation and perfectionism in English language learning: An analysis of Taiwanese students

intrinsic and extrinsic motivation. In M. R. Lepper \& D. Green (Eds.), The hidden costs of reward: New perspectives on the psychology of human motivation (pp. 109-148). Hillsdale, NJ: Lawrence Erlbaum Associates.

Lepper, M. R., Greene, D., \& Nisbett, R. E. (1973). Undermining children's intrinsic interest with extrinsic rewards: A test of the "overjustification” hypothesis. Journal of Personality and Social Psychology, 28, 129-137. http://dx.doi.org/10.1037/h0035519

Lim, D. H. (2004). Cross cultural differences in online learning motivation. Educational Media International, 41(2), 163-173. http://dx.doi.org/10.1080/09523980410001685784

McDonough, S. (2007). Motivation in ELT. ELT, 61(4), 369-371. http://dx.doi.org/10.1093/elt/ccm056

Mills, J., \& Blankstein, K. R. (2000). Perfectionism, intrinsic vs extrinsic motivation and motivated strategies for learning: A multidimensional analysis of university students. Personality \& Individual Differences, 29(6), 1191-1204. http://dx.doi.org/10.1016/S0191-8869(00)00003-9

Miquelon, P., Vallerand, R. J., Grouzet, F. M. E., \& Cardinal, G. (2005). Perfectionism, academic motivation, and psychological adjustment: An integrative model. Society for Personality and Social Psychology, 31(7), 913-924. http://dx.doi.org/10.1177/0146167204272298

Onwuegbuzie, A. J., \& Daley, C. E (1999). Perfectionism and statistics anxiety. Personality and Individual Differences, 26, 1089-1102. http://dx.doi.org/10.1016/S0191-8869(98)00214-1

Oxford, R. L., \& Shearin, J. (1994). Language learning motivation: Expanding the theoretical framework. The Modern Language Journal, 78, 12-28. http://dx.doi.org/10.1111/j.1540-4781.1994.tb02011.x

Pacht, A. R. (1984). Reflections on perfection. American Psychologist, 39, 386-390. http://dx.doi.org/10.1037/0003-066X.39.4.386

Paul, P., Ludwi, M., \& Andrew L. M. (1962). Student factors in foreign language learning. The Modern Language Journal, 46, 160-170. http://dx.doi.org/10.1111/j.1540-4781.1962.tb00811.x

Ryan, R. M., \& Deci, E. L. (2000a). Intrinsic and extrinsic motivations: Classic definitions and new directions. Contemporary Educational Psychology, 25(1), 54-67. http://dx.doi.org/10.1006/ceps.1999.1020

Terry-Short, L. A., Owens, R. G., Slade, P. D., \& Dewey, M. E. (1995). Positive and negative perfectionism. Personality and Individual Difference, 13(5), 663-668. http://dx.doi.org/10.1016/0191-8869(94)00192-U

$\mathrm{Wu}$, Yin-Yi. (2003). Intrinsic motivation and young language learners: The impact of the classroom environment. System, 31, 501-517. http://dx.doi.org/10.1016/j.system.2003.04.001 
Chen, K. T.-Z., Kuo, J. Y.-Z., \& Kao, P.-C. 